\title{
Development of methodological approaches to risk management within the system of internal control of agricultural organizations
}

\author{
Galina Khulkhachieva*, Lag Badmahalgaev, and Natalya Berikova \\ Kalmyk state University named B.B. Gorodiovikova, 358000, 11, A.S. Pushkin Str., bldg. 1A, Elista, \\ Republic of Kalmykia, Russian Federation
}

\begin{abstract}
In order to form methodological approaches to risk management of agricultural organizations, the article considers the grouping of risks according to various criteria, which allows them to predict them in a timely manner and minimize possible damage. A model of risk-oriented internal control is offered, the main purpose of which is to correctly identify risk factors that affect the production and financial results of an agricultural organization. Timely identification and assessment of potential risks will reduce losses caused by the impact of negative natural and climatic risk factors, and ensure the further stable functioning of agricultural production. The developed model of riskoriented internal control will help to identify existing problems in the organization in risk management to ensure the efficient and continuous operation of an agricultural organization.
\end{abstract}

\section{Introduction}

In the conditions of the modern economy, during the period of introduction of bilateral economic sanctions, not only problems in the functioning of the economy as a whole, state support for the agricultural sector are aggravated, but also shortcomings in the systematization and regulation of risks at the level of individual agricultural producers, which usually do not manifest themselves in a stable economy, have become actual.

Agricultural production is most susceptible to all kinds of risks of a different nature, accompanying all stages of production, sales of products, in contrast to other industries. This fact is due to the fact that the production cycle does not coincide with the calendar year, has a long period, agricultural production is characterized by seasonality.

Insufficient study of these problems, considering the industry specifics, the practical need to improve the quality of risk management in the agricultural production system determined the relevance of the chosen topic, the goal and objectives of the study dedicated to development of recommendations for development of methodological approaches to risk management within the framework of the internal control system of agricultural organizations.

\footnotetext{
*Corresponding author: borkaeva@mail.ru
} 
The study of the problems of improving the scientific concept of risk-based internal control is devoted to the papers of such economists as R. Alborov, V.D. Andreev, V.V. Burtsev, N.A. Goloshchapov, E.M. Gutsait, A.V. Evdokimova, J. K. Lobbek, A.K. Makalskaya, S.M. Pankova, I.N. Pashkina, A.M. Sonin, L.V. Sotnikova, A.A. Terekhov, O. I. Shvyrev and many others.

Wherein, there is a need for further analysis of industry risks, in carrying out their detailed grouping, forming methods for forecasting, and minimizing risks.

\section{Methods}

The purpose of this article is formation of theoretical and methodological provisions for effective risk management inherent in agricultural activities, within the framework of the functioning of internal control.

The scientific novelty of the study lies in the classification of risks inherent in agriculture, considering the industry specifics, development of a risk-based internal control model in 7 successive stages in order to predict, analyze and minimize risks.

In this article, using the methods of economic and statistical analysis, methods of analysis and synthesis of economic information, the risks of agricultural activities were grouped and classified, the methodology for predicting them within the framework of internal control was determined.

\section{Results}

Agricultural risk means the threatening probability of a loss of profit as a result of the onset of failure, damage to crops, the failure of large and small livestock, poultry due to the impact of unfavorable factors.

In order to form methodological approaches to risk management of agricultural organizations, it is necessary to group risks according to various criteria, which makes it possible to predict them in a timely manner and minimize possible damage.

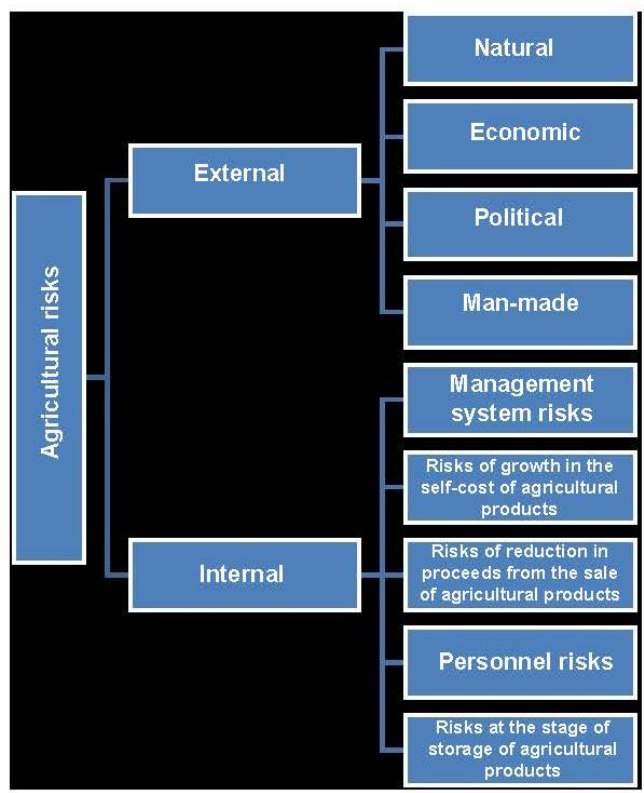

Fig. 1. Classification of agricultural risks in terms of their occurrence. 
According to the area of occurrence, the risks of agricultural production can be divided into internal and external ones. External risks include natural, economic, political, and manmade ones. Internal risks are understood as risks of the management system, risks of growth in the cost of agricultural products, risks of a decrease in revenue from the sale of agricultural products, personnel risks, that is, those caused by internal reasons, conditions and factors.

The greatest impact on agricultural production from the group of external risks is exerted by natural risks. Let us consider these risks in more detail, since these risks are the most significant and difficult to predict. For agricultural organizations of the Republic of Kazakhstan, climatic risks play a significant role, since the territory of the Republic of Kazakhstan is a zone of risky agriculture and animal husbandry.

Natural risks are understood as the impact on production of climatic conditions, temperature regime, and natural disasters.

Weather changes determine the features of production processes of a certain period, the financial results of organizations. In the territory of the Republic of Kalmykia, the impact of unfavorable weather conditions is significantly manifested. Agriculture is greatly influenced by drought, dry winds, strong gusty winds, little snow.

In the steppe zone, drought affects the dynamics and the total yield of cereals, various types of forage crops, and the volume of forage crops in animal husbandry to the greatest extent on the conditions of farming and on the results of production activities in general.

The internal control service needs to assess the effectiveness of measures to minimize drought losses and select the least costly and most efficient from the point of view of rationality. In various situations, an increase in the sown area of winter crops, the accumulation of autumn-winter moisture, an expansion of the species and varieties of the composition of sown crops can be used.

The climate of the Republic of Kalmykia is characterized by a strong gusty wind, which is complicated by absence of perennial plantings. A strong gusty wind in spring leads to blowing out of seeds, which causes significant material damage to the organization. Strong gusts of wind in late summer and early autumn can cause lodging of crops. In order to minimize the loss of lodging of crops, it is necessary to use a separate harvesting technology when mowing at a low cut, which in turn improves the species and varietal composition of crops.

In an arid zone prone to desertification, dry winds characterized by a deficit of moisture are considered frequent occurrences, with wind speeds exceeding $8 \mathrm{~m} / \mathrm{s}$. Dry winds lead to a suspension of development of plants and their further failure. In the initial growing season in agriculture, long continuous dry winds can lead to the failure of plants, which is characterized by significant material damage.

For successful enterprise management it is necessary to have detailed timely information about meteorological data, actual and statistical data. Formed forecast values, statistical data make it possible to choose the most optimal management decision, thereby reducing the expected damage to the minimum values.

An important aspect of increasing yields is improvement of the qualitative composition of soils. The ability to increase grain production without expanding the sown area gives an additional competitive advantage to agricultural organizations, which manifests itself in savings and profit from the sale of additionally harvested crops. The maximum yield is achieved in agricultural organizations in those areas where the soils are more fertile. The main direction of increasing soil fertility is to increase the content of nutrients in humus due to introduction of mineral and organic fertilizers [7]

Economic risks shall also be classified as external risks. Economic risks are manifested by the possible impact of the dynamics of the market situation, changes in exchange rates, a 
stronger tax burden, high inflation, a slowdown in the country's GDP growth, and a decrease in effective demand for agricultural products.

For example, Russia's accession to the WTO took place on the terms of the yellow (amber) basket, according to the obligations of which state support for the agro-industrial complex (subsidies) will be reduced from a possible 9 billion dollars in 2015 to 4.4 billion dollars in 2021 [6].

Internal risks are due to reasons arising within the agricultural organization. These include administrative risks, risks of an increase in the cost of production, a decrease in sales proceeds, risks of storing finished agricultural products.

The increase in the number of unprofitable farms is caused by both external and internal factors that restrain the growth of profits in the agricultural sector of the economy. Some of the main negative external factors are:

- imperfection of the mechanism that protects domestic agricultural producers from dumping the prices of imported agricultural products;

- imperfection of the investment policy for development of a logistics system for warehousing and transportation in the export of domestic agricultural products;

- insufficiently developed system for assessing the quality of domestic agricultural products, which does not allow fully exporting environmentally friendly agricultural products;

- lagging behind in development of transnational investment processes to diversify domestic agricultural business abroad, an inadequate share of lobbying for domestic interests in world food markets.

The main negative internal factors:

- price disparity between agricultural products, fuels and lubricants, industrial products;

- imbalance in domestic trade in the country's economy; - insufficient state investment support for modernization of fixed assets. [5]

Risks can also be classified due to occurrence of man-made risks that depend on human activities, natural risks that cannot be influenced by humans, and combined risks that represent indirect climatic consequences of human economic activity (ground collapse during construction works).

The peculiarities of the risk situation in agriculture are that the production technology is associated with the natural processes of development of biological organisms, the vital activity of which is directly dependent on natural conditions. This circumstance determines the negative, to some extent harmful consequences of unfavorable natural phenomena, due to the impossibility of their accurate forecasting.

According to the degree of accuracy in predicting risks in an agricultural organization, it is possible to identify risks that are predictable and non-predictable.

Predictable risks are risks associated with cyclical development of the macro and microeconomics, the planned development of competition in the developed market segment, seasonal risks typical for agriculture. The forecasting level fluctuates for different risks due to their specification in relative terms.

Risks that cannot be predicted include completely unpredictable phenomena and events, force majeure in agriculture.

According to the amount of possible damage, risks must be classified into:

Acceptable risk, when the possible damage will not exceed the expected volume of net profit from this operation;

Critical risk, when the probable losses will not exceed the expected gross profit;

Catastrophic risk, when the possible losses will be equal to the amount of equity capital.

According to the structure of risks, risks are divided into simple ones, which are not structured into subgroups, subspecies (inflation risk), and complex ones, subdivided into 
several subspecies (natural risks are subdivided into risks of frost, dry winds, drought, and etc.).

In agricultural organizations, risks can also be classified according to the types of financial consequences:

Risks, the negative consequences of which are characterized by economic losses, loss of profits, equity capital (penalties for violations of the conditions for supply of feed due to ice);

Risks, when the enterprise misses a possible profit, that is, under certain circumstances, the agricultural organization cannot implement the planned activities in order to generate income (the implementation of timely selective measures due to weather conditions that make it difficult to travel to livestock crews);

Mixed risks, the consequences of which are both economic losses and lost opportunities.

Risks are classified by frequency of manifestation:

Permanent risks are characterized by possible manifestations throughout the entire production period (inflationary risk);

Temporary risks appear only at certain stages of the production cycle (the risk of equipment failure during harvest).

Depending on the possibility of insurance, risks can be divided into:

Insured ones - risks that are subject to insurance;

Uninsured ones - risks that are not subject to insurance, are not included in the list of risks of insurance products.

It is not possible to completely eliminate the uncertainty of the operating environment of the enterprise. However, management managers, stakeholders and other information users shall have maximum awareness of the risks of the enterprise, as well as the degree of effectiveness of their controlling system. [16]

Today, the need has grown for development of methodological approaches to arranging a set of measures for risk management within the framework of the internal control system of agricultural organizations.

The purpose of risk-based internal control is to correctly identify the risk factors that affect the production and financial results of an agricultural organization.

This is due to the fact that in Russian agricultural organizations the system of internal control and risk management is underdeveloped at the present time, which does not meet the requirements of the modern economy.

The main objectives of risk-based internal control are as follows:

- systematization and grouping of risks inherent in agriculture;

- assessment of the influence of negative factors on the object of risk, assessment of the probability of losses and damages of their impact, determination of the gradation, assessment criteria;

- determination of methods for forecasting and minimizing risks in agricultural organizations.

\section{Discussion}

Agricultural production is exposed to numerous risks, both natural and man-made ones. Timely forecasting and risk assessment will minimize damage and losses caused by the impact of negative natural and climatic risk factors, and ensure the further stable functioning of agricultural production.

For agriculture, both in Russia and abroad, high-risk production is inherent, however, the production risks of this industry remain poorly understood both in domestic and foreign references. [9] 
The main way to reduce the impact of risk factors is their timely forecasting and analysis, which can be successfully implemented within the framework of internal control.

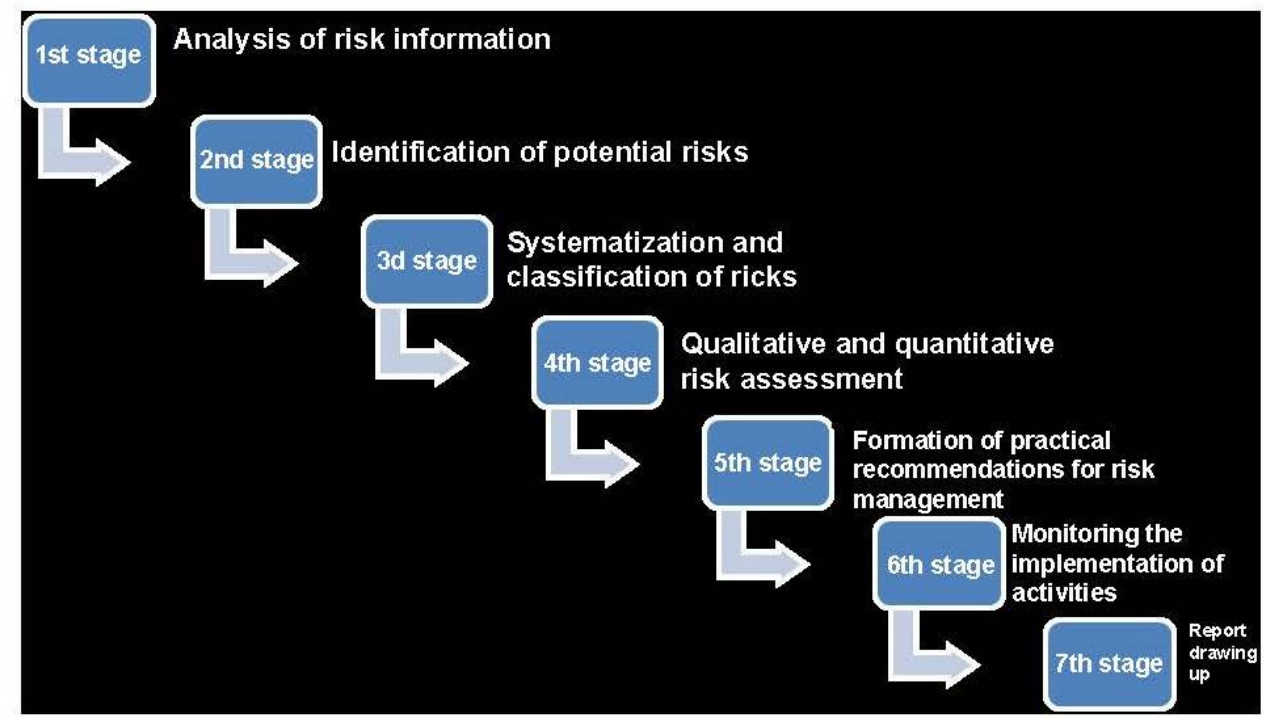

Fig. 2. Classification of agricultural risks in terms of their occurrence.

To build a model of risk-based internal control, it is necessary to distinguish 7 sequential stages:

At stage 1, it is necessary to analyze the information about the risks. The sources of information are: accounting statements of the organization, zootechnical and agronomic reports, data from veterinary services, organizational structure, production process diagram, data on the cost of production, meteorological data, financial and production plans of the organization, and etc.

Stage 2 is the identification of potential risks, determination of the degree of their impact on the production activities of the enterprise.

Agriculture is characterized by specific risks associated with the specifics of production activities, which in turn makes it difficult to carry out internal control in the organization.

Weather conditions directly affect the yield of agricultural crops, production costs, profits, sales volumes. For the Republic of Kalmykia, weather conditions periodically have an adverse effect on agricultural crops. In some areas of Kalmykia, drought leads to the loss of crops, dust storms, dry winds, and other natural phenomena cause significant damage to crop production and animal husbandry.

The biological nature of the resources of agricultural production and the main, byproducts obtained at the output will predetermine the sequence of technological operations, the violation of which may cause the risk of loss of products or a decrease in its quality. Sowing agricultural crops, harvesting earlier or later than the established deadlines, violation of the storage conditions for products, are accompanied by the risks of an increase in the cost of production, and decrease in profits.

The risk-oriented internal control is influenced by the high dispersion of the objects of inspection. Large distances between field, sowing teams, livestock camps complicate process control and lead to additional production risks.

In agriculture, risks are intertwined, both specific to the industry and common to many sectors of the national economy, which, in an unfavorable combination of all circumstances, in the aggregate can lead to catastrophic consequences for the organization. 
At Stage 3, systematization and classification of risks in an agricultural organization is carried out.

When identifying and systematizing risks, it is more expedient to classify them from the perspective of the sphere of occurrence: external and internal.

External risks do not depend on the activities of the enterprise, they arise from outside due to the volatility of the financial market, the variability of natural conditions, economic instability in the country and around the world. This group includes: natural, economic, political, man-made risks.

Internal risks shall include the risks associated with production activities of the enterprise, risks in the field of personnel management, financial assets, equity capital, everything that is directly dependent on the production activities of the enterprise, its management system and is subject to the impact of effective risk management of a particular enterprise.

The task of internal control is to assess the impact of each risk factor, grading according to the degree of significance. When analyzing various risk factors for agricultural production in the Republic of Kalmykia, it was determined that the greatest damage is caused by unfavorable weather conditions.

At Stage 4, it is necessary to conduct a qualitative and quantitative assessment of the specific potential risks of the organization.

In a qualitative risk assessment, it is necessary to determine potential risks, their sources and causes of occurrence, the most vulnerable production processes at risk, to predict the practical benefits and possible negative consequences of the risk manifestation. Based on the results of a qualitative analysis of risks, the most significant ones for their quantitative analysis are identified.

In the process of quantitative analysis, the probable damage of specific risks is calculated, and a cost estimate from the manifestation of risk is formed. For quantitative assessment, the tools of the theory of probability, mathematical statistics, and economic analysis are used.

At Stage 5, within the framework of internal control, it is necessary to formulate practical recommendations on risk management in order to reduce them and increase the financial stability of the organization.

Risk mitigation measures make it possible to reduce the likelihood of adverse events, reduce the amount of possible damage from the impact of adverse factors.

Risk management tools are diversification of production sectors, vertical integration, agricultural insurance, and formation of reserves. It is possible to reduce the impact of various risks by diversifying production, which allows to choose the optimal system of various types of production activities, minimizing internal risks, which will lead to an increase in the stability of the enterprise. Use of the procedure for self-insurance of potential risks involves the reservation within the organization of a certain part of free financial resources in the form of reserve capital, target reserve funds, insurance stocks of material and financial resources in order to neutralize possible risks.

Risk management in agriculture is hampered by the following problems:

- lack of structural units in the enterprise management system responsible for identifying and minimizing risks;

- lack of qualified personnel in the field of risk-oriented control considering the industry specifics;

- the applied methods of risk management are focused on eliminating the consequences of the manifestation of risk situations, not on their prevention and reduction of negative consequences.

When formulating measures to reduce risks in crop production, it is necessary to consider weather conditions, since they play an important role in duration of the spring 
sowing period, field work, harvesting, and procurement of fodder for livestock. Reducing the self-cost of production can be achieved through formation of a rational schedule for use of the machine and transport fleet of the enterprise, cost-effective routes for movement of agricultural machinery from one field to another, maintenance systems. For grain enterprises, in order to reduce risks, it is acceptable to develop a plan for distributing the harvested crop by currents and distributing it among granaries, a plan for selling grain to receiving points, and preparing funds for storing seeds.

In order to reduce risks in use of agricultural machinery and equipment, it is necessary to carry out measures for preliminary overhaul of obsolete machinery and equipment before carrying out major work, which will lead to a decrease in breakdowns and equipment downtime.

The anti-risk measures in use of machinery and equipment also include ensuring the constant availability of the most frequently out of order spare parts. Prompt repairs will significantly reduce time and reduce adverse effects on production as a whole.

The cultivation of mutually insured grain crops (sunflower and corn, wheat and rye), which differ from each other in their different reactions to weather conditions, contributes to the reduction of costs in crop production.

Weather conditions affect animal husbandry to a lesser extent than crop production, as it is characterized by the constancy of the work performed, the compact arrangement of livestock crews.

Anti-risk measures in crop production are aimed at determining the work, their timing, performers, technical means, in animal husbandry, these measures are aimed at forming the timing of the output of products, its volumes, quality, the condition of animals, conducting timely zootechnical and veterinary measures.

Regardless of the sectoral specifics of an agricultural organization, it is necessary to carry out timely forecasting of revenue, production costs, gross and net profit, growth in enterprise production, and prices for agricultural products. [1]

Actions of risk-oriented control at Stage 6 are aimed at reducing risks to an acceptable level, monitoring the implementation of measures to predict and reduce adverse factors, and analysis of the results obtained.

The efficiency of the risk-based internal control system is determined using utility criteria, which include:

Timely informing the administration, the management of the agricultural organization about the problems identified in the process of implementing control;

Low level of expenses for implementation of control activities, its high profitability;

Development of specific recommendations for eliminating deficiencies.

At the final Stage 7, a report is generated on the results of the risk-oriented internal control to be submitted to the organization's management.

Agricultural organizations are characterized by some internal adaptation mechanisms, which allows the industry to compensate for losses from certain risks, to reduce the level of risk.

Some types of agricultural products have a low elasticity of demand against fluctuations in market prices and incomes of the population due to the fact that they are products of basic necessities and daily demand.

In agriculture, one of the main means of production is land, which is not subject to physical, moral deterioration; with rational use, its productive capabilities and, accordingly, the market value of the land plot increase.

In animal husbandry, adaptive capabilities are characterized by acceleration of reproduction in some subsectors (pig breeding, poultry farming), in which high productivity is observed, which in turn is a factor that reduces the risks of an organization. In an 
unfavorable combination of circumstances, the enterprise has the opportunity to switch to products that are less costly and more productive.

\section{Conclusion}

Therefore, we can conclude that the agro-industrial complex in general and agriculture in particular have their own adaptive mechanisms or, figuratively speaking, have some kind of "anti-risk antidote". For real use of these opportunities, it is necessary that decision-makers are able to correctly assess the level of risks, choose a sound strategy and tactics of economic activity in a market environment.

The developed model of risk-oriented internal control will help to identify existing problems in the organization in risk management to ensure the efficient and continuous operation of an agricultural organization.

\section{References}

1. I.N. Bogataya, V.I. Kovaleva, Collection of scientific articles of the International Scientific and Practical Conference (2021)

2. N.V. Zhahov, E.A. Aleeva, V.S. Krivoshlykov, E.S. Nesenyuk, Proceedings of the 33rd International Business Information Management Association Conference (IBIMA 2019, Education Excellence and Innovation Management through Vision, 2019)

3. V.S. Krivoshlykov, N.V. Zhahov, A.L. Borodin, M.V. Shatokhin, E.A. Gurkovskaya, L.V. Garipova, Proceedings of the 33rd International Business Information Management Association Conference (IBIMA 2019, Education Excellence and Innovation Management through, 2019)

4. I.G. Generalov, N.N. Kuchin, S.A. Suslov, I.V. Ryabova, A.A. Kurilova, International Journal of Advanced Biotechnology and Research, 10, 1 (2019)

5. N. Zakharov, European Journal of Political Economy, 56 (2019)

6. H. Zhang, R. An, Q. Zhong, China Journal of Accounting Research, 12, 1 (2019)

7. N.V. Zhahov, V.S. Krivoshlykov, M.V. Shatokhin, 30th International business information management association conference - Vision 2020: sustainable economic development, innovation management, and global growth (IBIMA, 2017)

8. N. E. Goryushkina, I. B. Vakhrushev, M. K., Akhmetova, O. V. Otto, E. V. Pesotskaya, N. E. Voinova, International Journal of Mechanical Engineering and Technology, 12, 9 (2012)

9. M. Wishnu, International Economics, In press, corrected proof (2019)

10. G. Khulkhachieva, E. Boldyreva, M. Sarunova, T. Allyaeva, D. Mandzhieva, The European Proceedings of Social \& Behavioural Sciences (2019)

11. G. Khulkhachieva, A. Markov, E. Uchurova, K. Pyurveeva, E. Godzhaeva, The European Proceedings of Social \&Behavioural Sciences (2019)

12. I. Generalov, S. Suslov, R. Bazhenov, A. Sibiryaev, E. Firsova, IOP Conference Series: Earth and Environmental Science. conference proceedings (Krasnoyarsk Science and Technology City Hall of the Russian Union of Scientific and Engineering Associations, 2020)

13. T. Khudyakova, A. Shmidt, International Multidisciplinary Scientific Conferences on Social Sciences and Arts (2016) 
14. S.G.C. Aditto, C. Christopher Gan, G.V. Nartea, Risk Management - Current Issues and Challenges (2012)

15. D.D. Elazegui, A.C. Rola, E. Allis, Lakes \& Reservoirs: Research \& Management, 21, 3 (2016)

16. V. Rossi, F. Salinari, S. Poni, T. Caffi, T. Bettati, Computers and Electronics in Agriculture, 100 (2014) 